\title{
STARTING AND STOPPING POINTS: A RESPONSE TO STAVROS GADINIS
}

\author{
Fleur Johns*
}

Open the website of the Financial Action Task Force (or FATF) ${ }^{1}$ and find your way to the "FATF Presidency" page 2 . Up until the end of June 2015, you would have encountered a headshot of a dapper fellow with smiling eyes and a pink bowtie: Roger Wilkins OA, President of FATF between July 2014 and June 2015. ${ }^{3}$ A one time "mandarin"4 of the public service in Australia (former Secretary of the federal Attorney-General's Department in that country), Mr. Wilkins seems an apt embodiment of those qualities that Stavros Gadinis would have us see in the FATF, as a "ministry executives" network..$^{5}$ It seems entirely plausible to cast Wilkins as a vehicle of such networks" "key motivation"- - to pursue "broad societal goals." "From his record, he seems well suited to the role of guardian of "states' interests" in a "secure environment," deft at deploying his "longstanding connections" and "power relations" in order to "strike deals" and, where necessary, unleash "sanctions' firepower." In short, Mr. Wilkins seems to "fit neatly within the three types—private, regulator, ministry" around which Stavros Gadinis' thought-provoking article revolves. ${ }^{8}$

Just a few years earlier, however (before 2008, to be precise), Mr. Wilkins might have occupied quite a different position among Gadinis" "three types." Working with Citigroup" as he then did, as global public sector leader on climate change and Head of the Government and Public Sector Group for Australia and New Zealand, Mr. Wilkins would have been invested with quite different motivations and predispositions in Gadinis' scheme. That is, he would have been ascribed with the properties of a private network participant presumed to "advocate for [a] vision on a global scale, free from ... the distortive influence of national politics," guided by a "deep understanding of market needs and opportunities" and the goal of "minimiz[ing] any government involvement with [his network's] activities."10

Stavros Gadinis' article is not, of course, about individuals such as Mr. Wilkins. Nor are Gadinis' ontological or predictive claims necessarily perturbed by the meanderings of Mr. Wilkins' career or the networks within networks suggested thereby. Nonetheless, I begin with Mr. Wilkins' trajectory in order to raise the question of starting and stopping points. Beginning with the network — a "concept [that] can conjoin anything," prone to "endless extension" and "fractal" replication—Gadinis is insistent upon "enact[ing] . . a stopping place," as

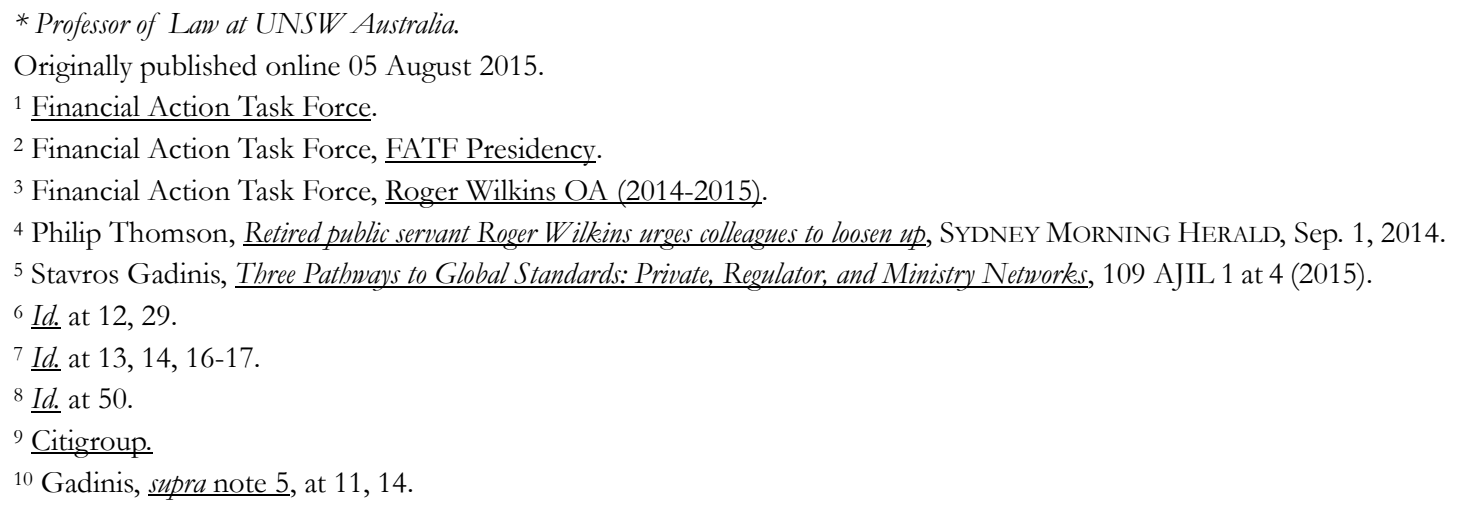


one must to mount any analysis. ${ }^{11}$ And the stopping point he prefers is the tripartite typology of networks mentioned earlier, most succinctly captured in Table 1 in his article: the three categories of "transnational regulatory network" comprised of private market participants, national regulators, and executive branch officials, respectively. ${ }^{12}$

In this short comment, I consider what might be at stake in scholars of international law settling, collectively, upon this particular stopping point, or what may be welcomed in, and shut out, by these intellectual and political lodgings. For if Gadinis would have us open up "the black box of network standard setting" and look beyond a "global chessboard" to scrutinize "actors with separate objectives and policy considerations," then surely it is in the spirit of his work to scrutinize the scholarly standard setting to which he may be contributing surrounding understandings of "transnational regulatory networks." 13 I will begin by examining the properties with which Gadinis invests all three networks, before considering each in turn and the ways in which they are understood to relate in Gadinis' scheme.

Before doing so, let me acknowledge and applaud the contribution that Gadinis has made in this article to scholarship on informal law making and hybridized public-private governance on the global plane. Moving beyond generalized concerns about accountability, Gadinis has shown these concerns to have "different shape[s]" in different network settings. ${ }^{14}$ To the black and white of public-private or soft-hard law dividesand conventional debates about movement in one or the other direction-Gadinis has added gradation, color, and allowance for "fail[ure]." 15 He has added, too, a set of well-defended hypotheses about when and why international standard setting may proliferate over treaties or harmonized national laws.

Nonetheless, the triptych of networks that Gadinis mounts for our viewing and veneration merits some critical attention.

\section{Networks Have Feelings Too}

One remarkable thing about the networks in Gadinis' account is how integrated, monadic, and static - in short, how unnetworked - they appear. This undercuts, somewhat, both the sense that Gadinis is grappling with a new or recent phenomenon and the sense of freshness that his own analysis carries. In Gadinis' rendering, networks seem virtually interchangeable with international institutions, more or less as the latter have featured in international relations and economic development scholarship for some time. Indeed, Gadinis says as much in extending certain claims that global administrative law scholars have made in relation to international institutions directly, without adjustment, to the networks of which he writes. ${ }^{16}$

Far from unraveling inwards and extending outwards into "continuous chain[s]" (as, for instance, in Bruno Latour's ${ }^{17}$ influential account of networks), Gadinis' networks have "bodies," "missions," "relationships," and "motivations." 18 They are strikingly anthropomorphic. What is more-for all the article's insistence on attending to diversity - they are more or less uniform in their anthropomorphism. Networks in all three categories

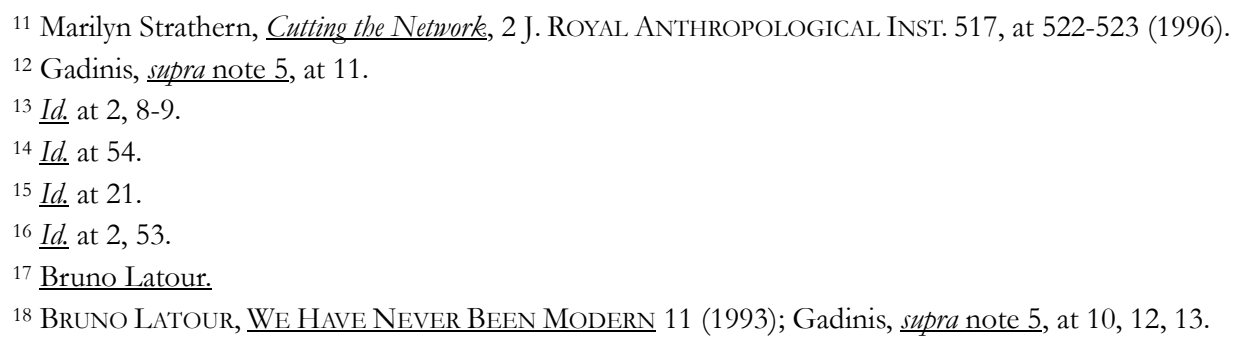


are understood to possess appetites for celebrity and affirmation. They aspire to "gain[] new followers" and to "boost their legitimacy."19

\section{No Politics Please, this is Private}

Among the further properties with which networks comprised of private participants, in particular, are invested is a predilection for "a-national[ism]," or for "safeguard[ing] . . . non-political, non-national" understandings of their work. ${ }^{20}$ This is perhaps unsurprising, but it is not the only interpretation of such private networks and their regulatory outputs available to Gadinis. After all, many decades' worth of feminist legal scholarship, and more than a century's work in social and political theory, have called into question the necessity, and illuminated the ramifications, of casting the private sphere, and work that people do in that sphere, as nonpolitical. ${ }^{21}$ In light of this intellectual tradition, it is noteworthy that Gadinis goes to no pains to explain or justify why readers should accept his characterization of private networks as "non-political" and "a-national."

Perhaps, to Gadinis, casting private networks' work and prevailing sensibility as nonpolitical is just a matter of fealty to the perceptions of network participants: he reminds readers late in the piece that his study is concerned with what network participants perceive, rather than what they actually are, have or do. ${ }^{22}$ Yet this seems unconvincing as an explanation of why private networks' regulatory work in the financial sector must be construed as nonpolitical. Large financial firms quite explicitly foster and advance political programs and ideals, sometimes as champions of a particular nation and sometimes otherwise. ${ }^{23}$ Moreover, private networks such as the Wolfsberg Group of Banks ${ }^{24}$ have long engaged in intimate collaboration on regulatory endeavors with the FATF, which Gadinis casts as the most political of networks in his scheme. ${ }^{25}$ That collaborative work is exemplary of the sorts of hybridization-precisely those links and leakages by which network analysis in other modes is most enlivened-that Gadinis' scheme does not entertain. ${ }^{26}$

\section{Regulatory Irredentism}

Alongside private market participants seeking ways around the "distortive influence of national politics," we encounter the über-distorters: national regulators, or rather networks of the same. ${ }^{27}$ 'These are, in Gadinis' account, forever on the hunt for "new policymaking tools that will enhance their ability to promote their regulatory missions and allow them to maintain and perhaps even expand their turf." 28 Whereas private market

\footnotetext{
${ }^{19}$ Gadinis, supra note 5 , at 7,8 .

${ }^{20} \underline{I d}$. at 15 .

21 Jeff Weintraub \& Krishan Kumar, Public and Private in Thought and Practice: Perspectives on a Grand DichotOMY (1997); Karl Marx, On the Jewish Question, in The MARX-Engels ReAder 26(Robert C. Tucker ed., 1978) (1843) Deborah L. Rhode, Feminist Critical Theories, 42 STAN. L. REV. 617 (1989).

${ }^{22}$ Gadinis, supra note 5, at 54.

${ }^{23}$ See, e.g., Karen Ho, Liquidated: AN ETHNOGRAPHY OF WAll STREet 73-122 (2009). For historical illustrations of this phenomenon, see PHILIP J. STERn, THE COMPANY-STATE: CORPORATE SOVEREIGNTY AND THE EARLY MODERN FOUNDATIONS OF THE BRITISH EMPIRE IN INDIA (2011)

${ }^{24}$ Wolfsberg Group.

25 Mark Pieth and Gemma Aiolfi, The Private Sector Becomes active: The Wolfsberg Process, 10 J. Fin. Crime 359 (2003).

${ }^{26}$ On networks and hybrids, see Strathern, supra note 11, at 521-522, and LATOUR, supra note 18, at 10-11.

${ }^{27}$ Gadinis, supra note 5, at 11.

${ }^{28} \underline{I d}$. at 12 .
} 
participants are depicted seeking "opportunities in the global marketplace" and responding to "market needs," regulators' aims are cast as proprietary and expansionist—in terms of the acquisition and defense of "turf." 29

Curiously, also, despite acknowledgment of their statutory mandates and public consultation procedures, regulators are cast as more deaf to the voices of constituents - more derisive of democratic input - than private network participants. While the latter remain responsive to "strong pressures ... to gain market endorsement," the former are described as "depart[ing] from constituents' suggestions should they choose to do so." ${ }^{30}$ Instead, regulator networks are, Gadinis tells us, "dominate[d]" by "concern for institutional autonomy" and "fears of disempowerment." 31 They are, in short, antinetwork networks.

Why regulator networks should play King Lear ${ }^{32}$ to private networks' Cordelia is never really explained in Gadinis' article. It is simply a matter of regulators' nature, it seems. And it is a premise from which much else by way of Gadinis' analysis seems to flow, and to do so naturally. It is, for example, implicitly on the basis of this sense of regulators' inherent neediness and fearfulness that Gadinis' rests his conclusion that "highly effective regulators" are especially keen to seek out "other highly effective regulators": notably more so, he suggests, than in the case of other networks. ${ }^{33}$

\section{The Power and the Public}

While regulators work to gain and defend turf in Gadinis' account, ministry networks are looking to "broad societal goals," with an eye to "electoral appeal." 34 At the same time, however, ministry officials are cast in a posture as defensive as that of regulators. They "need to safeguard states' interests" and hence keep their network negotiations "closed to the public." 35 (It is noteworthy that, in contrast, no reference is made to private networks' vigilance over confidentiality and proprietary information.) Ministry networks' activity doesn't seem to involve much learning, ambivalence, or movement in positions. Rather, Gadinis insists, "these networks promote objectives in line with their governments' overall political goals." ${ }^{6}$

Again, Gadinis' insights and findings line up neatly behind this premise. It is this characterization, for instance, that leads Gadinis to hypothesize that state-to-state "power relationships" are especially significant in the expansion of the FATF-since the FATF is cast as a ministry executives' network, despite the diverse backgrounds of FATF representatives—and to confirm that hypothesis through regression analysis. ${ }^{37}$

\section{Stakes and Statistics}

The effect of Gadinis stabilizing and building statistical models around these particular understandings of networks, or network "prototypes," is to affirm and extend the reach of some quite tendentious political and scholarly tenets. Among these is the idea that networks deemed private should properly be understood as merely servicing the market, while regulators and politicians' networks forever encroach and distort, seeking to entrench and expand their respective strongholds. Another is the claim that networks and institutions are more

\footnotetext{
${ }^{29} \underline{I d}$. at $11-12$.

${ }^{30} \underline{I d}$. at 13 .

${ }^{31} \underline{I d}$. at 15 .

32 WiLLIAM SHAKESPEARE, KING LEAR.

33 Gadinis, supra note 5, at 46.

${ }^{34} \underline{I d}$. at 12 .

$35 \underline{I d}$. at 13 .

${ }^{36} \underline{I d}$. at 15 .

${ }^{37} \underline{I d}$. at 46 .
} 
or less interchangeable and that each can and should be ascribed with willfulness and a coherent, fully resolved ambition comparable to that of a particular type of individual.

Gadinis claims to want to open networks to "noncore countries to voice disagreements and concerns" with a view to "improv[ing] [their] legitimacy." 38 In his analytical scheme, however, this prospect seems already radically foreclosed. It is not least foreclosed by the assumption that people in "noncore countries" should advance their concerns as countries and not, say, as participants in "a-national" private networks. In this respect, and in others outlined, assumptions do a tremendous amount of normative work in Gadinis' article.

Thus, for all its stated concerns, in its basic presuppositions, Gadinis' article seems strangely averse to openended reflection on "democratic values [that] may . . . be at risk" in a network of transnational regulatory networks. ${ }^{39}$ In a related sense, Gadinis' analysis seems oddly resistant to the "intersecting lines[,] ... interstices," and unruliness of the network form itself. ${ }^{40}$

In summary, Gadinis' article seems inattentive to the myriad possibilities of network analysis and incurious about the make-up of those networks around which it revolves. His prototypes are propped up by political assumptions that merit questioning in the name of the democratic values that he champions and yet those assumptions elude scrutiny. The pathways of inquiry that Gadinis lays down for his readers-to explore the lawmaking powers of network participants—seem, as a consequence, rather more manicured, patrolled, and well-trodden than one might expect, given the "novelty of the network phenomenon" to which he is drawn. ${ }^{41}$

${ }^{38} \underline{I d}$. at 57.

${ }^{39} \underline{I d}$. at 52 .

${ }^{40}$ Network, $n$. and adj., Definition, OXFORD ENGLish Dictionary.

${ }^{41}$ Gadinis, supra note 5, at 1 . 